\title{
Epistemological Foundations of Natural Sciences in Islam
}

\author{
Marziyehsadat Montazeritabar ${ }^{1,2}$ \\ ${ }^{1}$ Institute for the History of Natural Sciences, Chinese Academy of Sciences, Beijing, China \\ ${ }^{2}$ College of Humanities \& Social Sciences, University of Chinese Academy of Sciences, Beijing, China \\ Email:msmt@ihns.ac.cn
}

How to cite this paper: Montazeritabar, M. (2019). Epistemological Foundations of Natural Sciences in Islam. Open Journal of Philosophy, 9, 63-71.

https://doi.org/10.4236/ojpp.2019.92006

Received: December 19, 2018

Accepted: March 15, 2019

Published: March 18, 2019

Copyright (c) 2019 by author(s) and Scientific Research Publishing Inc. This work is licensed under the Creative Commons Attribution International License (CC BY 4.0).

http://creativecommons.org/licenses/by/4.0/

\begin{abstract}
Every scientific system relies on a particular civilization and cultural origin. Islamic science is no exception to this rule and is dependent on Islamic civilization and derived from its specific intellectual and epistemological system. This intellectual system that relies on the teachings of the revelation gives rise to an insight into the world as a metaphysical backbone and philosophical presuppositions in science and scientific work. Islamic science, based on Islamic epistemology, is influenced by religious propositions in various aspects. An Islamic scholarly tradition that emerged in the golden age of Islam is an example of this science. In this period of history, a close connection between Islamic worldview and epistemological foundations in all branches of science, especially natural sciences, can be established. Here, we have addressed the theory of Islamic science and discussed about the foundations of Islamic epistemology and its impact on determining the subject, purpose, and methods of research in the natural sciences in Islamic civilization. The present study discerns Islamic science as a science based on Islamic epistemology.
\end{abstract}

\section{Keywords}

Islamic Science, Epistemology, Natural Sciences, Islamic Worldview

\section{Introduction}

\subsection{Science and Religion}

For the first time, the debate on "science and religion" raised during the Renaissance. At that time, religion was considered as a formidable obstacle to advancement because of the sovereignty of the Church and due to the fact that some of the teachings of Christianity were contrary to the intellectual growth (Hall, 1994). Therefore, in order to be able to grow and make progress, scholars 
in the West had to confront Christianity. As a result of these struggles, it was gradually conceived that science and religion were considered as two separate entities and thus, a two-entity model of science and religion was formed which put these two elements in front of each other. Subsequently, this model was extended to all scholarly traditions, including the Islamic scientific tradition and all religions, including Islam (Iqbal, 2009).

Therefore, the West digested the knowledge inherited from the pre-modern era (both Greek and Islamic ones which had divine characteristics) in its worldview and created a new epistemological system called Science (modern science). Modern science was devoid of any religious and divine dimensions and lacked qualitative aspects, and only paid attention to quantities. This epistemological system recognized only itself to be able to identify the nature, and regarded any other knowledge system preceding it and in general, except itself (such as natural philosophy, natural history, occult sciences) as non-authoritative, or in other words, non-scientific (Barbour, 1968).

Since then, the discussion of science and religion and the relationship between them has been extensively examined and a variety of relations other than opposition and contrast have been gradually assume (Ferngren, 2002; Dallal, 2002). In general, types of relationships that have been made so far between science and religion are:

- Conflict: Science and religion are naturally fighting against each other.

- Independence: Science and religion are two completely autonomous and independent domains.

- Interaction: There is a common ground between science and religion for dialogue and they can benefit from each other's experiences.

- Unity: Science and religion both have epistemological and ontological claims about realities beyond the human world. Science and religion are both in the explanation of one world, as the goal of science is the discovery of order in nature, and we express this order as scientific laws. The purpose of religion is to understand the meaning and purpose of the world and what is our position in the world. Actually, religion provides a metaphysical background for science (Golshani, 2005).

\subsection{Islamic Science}

After a few centuries of domination of modern science and its consequences (including destructive and constructive consequences), in the contemporary era, an approach was proposed which can be called Islamic science (Nasr, 1981, 1993) due to its differences with the current ruling of modern science. On the contrary to the epistemology of modern science which has a predominantly positivist nature and is detached from traditional metaphysics and philosophical theology, theory of Islamic (sacred, or theistic) science calls for a return to the religious-oriented system of knowledge, an epistemic system in which the quantity and quality are both taken into consideration (Nuseibeh, 1996; Azram, 2012). In other words, the intention of this approach is not to limit the science and refer it to the reli- 
gion, but to rescue science from materialism and secularism and to reverse the secularized science into its original nature.

The impressions taken from Islamic science and the definitions presented are different (Stenberg, 1996; Kalin, 2002). There are mainly two types of perceptions of Islamic science. The first thought about Islamic sciences is the sciences that are extracted from Qur'an and Sunnah as scientific miracles and contain empirical scientific facts. Islamic science, in this sense, has provoked strong criticism from both the proponents and opponents of the theory of Islamic science. Fundamentalists claim that any startling discovery of modern science has been predicted in Qur'an. However, in this regard, there would never be a contradiction between holy (sacred) texts and scientific experiences and statements because it is always possible to interpret holy texts in such a way to be in accord with scientific experiences and facts (Hoodbhoy, 1991). On the other hand, given that falsification is a feature of scientific propositions and scientific statements are fallible, if one tries to adapt scientific facts to the holy texts, then the invalidation of scientific fact over time will discredit sacred texts as well (Golshani, 2005).

Another existing thought is that Islamic science is a science which is based on Islamic epistemology and its subject, purpose, and method are influenced by religious propositions. In this view, religious teachings and non-religious metaphysics are both contained within the context of empirical sciences. The advocates of Islamic science in this sense believe that science is not formed in a vacuum, and any science is influenced by a particular worldview (Golshani, 2005; Nasr, 1981). They assert that Islamic science is a science that forms within the framework of Islamic monotheistic worldview and is the antithesis of secular science (Golshani, 1998). Whether a science or knowledge is Islamic or not can be realized only by proper methodology and revelation-cited logic. For a science to be Islamic, only conceptual and epistemic communication is not sufficient; rather, this relationship must be methodical and logical. That is, if a scientific system was reasonably cited to revelation, it can be called Islamic. It is not true to say that the circle of sensational sciences is cut off from the circle of authority (validity), and each of them has its own method; instead, their authority originates from their harmony with revelation, so this orientation should become the logic and principle.

There must be a logical and methodological relationship between natural sciences and the teachings of revelation. In Islamic view, natural sciences have a direct relationship with revelation. Getting to the truth is same as the journey from the appearance to the inward (esoteric) dimension. Only revelation can make this journey possible and draw man from the appearance of his existence to his inner dimension (Nasr, 2005). In the religious culture, revelation and experience are interconnected in the sense that human's consciousness and knowledge-whether achieved by ordinary and fallible methods such as intellect, experience, and intuition or obtained through the unusual and infallible way of revelation-have an intellectual explanation. 
Of course, this relationship is a mutual relation in the sense that the empirical method should match the revelation and also, the method of revelatory teaching must be rationally proved. In Islam, the principles of religion are rational principles and should be corroborated by reason. One of methods of proving monotheism, which is the first and most important principle of religion, lies in natural sciences. That is why in Islam it is highly advised to learn science or wisdom. Therefore, natural sciences greatly help to strengthen the monotheistic insight of the scholar.

Islam not only encourages its followers to learn sciences, but it also provides general rules of sciences and teaches the fundamentals of many sciences including empirical sciences. Indeed, some intellectual rules can be extracted from religious texts (Qur'an and Sunnah) in order to recognize the epistemological framework of natural sciences.

\section{Relationship between Islamic Worldview and Natural Sciences}

So far, extensive research has been conducted about Islamic science, and Islamic science has been introduced as a model of science. On the other hand, it has been said that this model-Islamic science-has already existed in history as well (Nasr, 2007), referring to the Golden Age of Islam from the 8th to 13th centuries CE (Turner, 1997) (Falagas, Zarkadoulia, \& Samonis, 2006). During this period, natural sciences were regarded as part of philosophy; they were taught along with mathematics and theology and all of them were embedded within a single metaphysical framework, called as Islamic worldview (Abdullah \& Nadvi, 2011; Qutb, 2006). The scientific tradition that was created in Islamic civilization and flourished in the eighth century can be regarded as an example of Islamic science (Iqbal, 2009). In this scientific tradition, there is a close connection between the Islamic worldview and the epistemic foundations of natural science. In the following, we will continue to discuss about these principles.

\subsection{Subject of Natural Sciences}

The subject of natural sciences is the natural objects ${ }^{1}$, their incidental properties, and their "four causes" (Al-Farabi, 1996; Ibn Sina, 1983). Natural science is concerned with things that cannot exist except in material bodies. However, as in monotheistic worldview the objects and phenomena are not accidental and all of them have causes, the material bodies are studied in natural sciences with their four causes (matter, form, agent, the end). In the view of Ibn Sina, a question about a natural phenomenon is a query about the "four causes" of that phenomenon.

Natural sciences are divided into eight components (Al-Farabi, 1996). The first types are study of "the basics of variables" such as time, space, motion, inertia, the extremity (end), and infinity. The second component is the study of hea-

${ }^{1}$ Objects refer to the bodies that their existence is obvious. 
vens (sky) and the universe, which deals with the recognition of compound objects and precepts of primal (simple) objects, whether in sky or on earth. The third type is generation and corruption which is aimed at understanding the foundations, the four elements, and transformation of the forms of the matter. The fourth one is studying meteorological phenomena and understanding the cause of natural events such as lightning, rain, snow and earthquakes. The fifth component is mineralogy which is about the quality and composition of materials. The sixth type is botany. The seventh component is zoology. And, the eighth type is psychology which returns to the mankind.

\subsection{Ultimate Purposes of Natural Sciences}

The main objective of natural sciences can be introduced as explaining and understanding the world of nature. In the course of the history of the scientific thinking of Islamic thinkers, the ultimate goal of science was mostly to interpret and describe the universe. Many Golden Age scholars point out in their introductory part of their works that their goal of writing texts is to acquire the truth. Hence, the science itself had mattered for them and the science alone did not have an instrumental aspect.

Another purpose in natural sciences is to recognize God. In Islamic insights, natural phenomena are like the signs of Allah (God). Therefore, the recognition of nature is also considered as the recognition of Allah's signs and this is a way of recognizing Him.

Furthermore, the goal of science is the perfection and actuality of the human intellectual talent, and this is the same as what can be perhaps brought into the definition of "wisdom": It makes human a rational universe and this rational universe is similar to the objective (concrete) world.

It should be noted that in the Islamic epistemology, the purpose of science is not just to interpret and describe the system of the universe, but also to find the right ways to grasp the nature. Therefore, one of the goals or results of science is the acquisition of the ability to provide human well-being.

\section{Research Methods in Natural Sciences}

In the Islamic thought, the first and most basic tool for cognition is the five senses. In the Qur'an, there are several verses in which human beings are encouraged to use senses. A telling example is:

"And Allah has extracted you from the wombs of your mothers while not knowing a thing, and He made for you hearing and vision and intellect that perhaps you would be grateful." (Qur'an, 16:78)

In this verse and similar verses, the human is reminded that these blessings (in this case, the senses) are given to human by Allah, and now human has to be thankful and grateful. This thanksgiving means to take advantage of the blessings (senses) in the correct direction.

One of the means of cognition for man is his senses. It is clear that every hu- 
man being communicates with the surrounding world first through the senses, and if he lacks one of the five senses from his birth, then he will be deprived of the specific perception set of that sense. Anyone who lacks a type of sense, he lacks a type of cognition.

In cognition of nature, which begins with recognizing tangible objects, there is no choice but to use the senses. This is due to the fact that human beings gain power by utilizing their five senses to approach the natural world. Islamic scholars were the first to use the scientific observation method by providing conditions arranged to control experiments (Hunke, 1960). In the works of the Islamic scholars of the Golden Age, we will frequently see their description of observations. Ibn al-Nafis, a Muslim physician in the seventh century CE and explorer of pulmonary circulation of blood, explains his method of work (Al-Nafis, 1988):

"In order to introduce the action of each body's organ, our support is only the careful examination and honest analysis of that organ. And, without considering if it matches the teachings of the predecessors or not."

In recognizing the nature, it is highly necessary for the sensory cognition of human to be combined with one kind of action and this action is experiment. This method was one of the privileges of the Islamic period to the Greek period. Muslim scholars not only used this method very much, but they themselves were also the founders and innovators of this method.

Certainly, the best way to evaluate the sensual cognition is to test that. However, the point here is that in Islamic sciences, the experiment alone is not the criterion of the authenticity of knowledge; this in contrary to modern science wherein the criterion for the correctness of knowledge is the action and experiment. According to modern science, if a hypothesis successfully comes out an experiment, it is then a correct hypothesis. However, in Islamic sciences, although experimentation and practice are recognized as one of the means of cognition, the criterion of the correctness of cognition or scientific hypothesis is not examination, but it is rational principles. Even, in a situation where the veracity of hypothesis is tested by experiment and the hypothesis is validated by the experiments, then the criterion for success of that hypothesis is still the rational principles involved in testing, not the experiment itself.

In each experiment there is a hidden deduction which is a straightforward intellection and inference that has no base of feeling and experience. This deduction is as follows: there exists an obvious primary principle intrinsically in every human's wisdom. This obvious principle, that all human beings accept it and have it, is: Similar objects will have the same verdict, whether that judgment is positive or negative. In other words, the precept of each object will be also the precept of other objects like that object. That is, if we have similar things that have no difference (their nature is the same, their conditions are the same, and there are no differences between them in any way), and if they are merely two individuals of the same essence, then if one of these essences has a property, it is impossible for the other essence to lack that property; otherwise, it would be 
"distinction without a difference"2 which is impossible (Al-Tusi, 1947).

For this reason, in Islamic epistemology, the method of experience has a discursive and certain validity. This is contrary to the induction, which is a pure sense and has a conjectural validity. The reason for this is that the criterion of generalization in experiment is the intellect and rational principles. Actually, the reason for the uncertainty of sciences that are merely documented by experiment is that the assumptions made in sciences do not have any reason and evidence except conforming to the action and resulting in practice. However, resulting in practice is not the reason for the veracity of a hypothesis and its correspondence to the truth. This is due to the fact that it is possible for a hypothesis to be completely incorrect but at the same time, it can be verified in practice. A telling example for this case is the Ptolemy's Board that was considering Earth as the center of the universe, and the planets, the Sun, and all the stars were moving around Earth. While this theory false, they concluded from this false hypothesis about the eclipse of Sun and Moon, and so on.

All of the mentioned cognitive means are necessary to gain knowledge, but they are not sufficient. The forms and the matters of most of natural objects are insensible, and the truth of their existence is proven only by deduction and proof (Al-Farabi, 1996). In researching about nature, in addition to the method of observation, induction and experience, we need argumentative and deductive methods because many principles and assumptions of natural sciences are provided from metaphysical and philosophical theology and the power of intellect. The realm of the empirical method has a specific extent for Muslim scholars and this method cannot be used in all areas and for all researches. Sensory and experimental methods are used only to identify the tangible nature and the appearance of objects. And the origin of objects and the truth of nature cannot be identified by senses and experiments.

Argumentation is connecting a number of known things to discover an unidentified and unknown thing. In the view of experimentalists, the unique way to acquire a new knowledge is to make a direct contact with objects through the senses, so the only correct way for investigating in the objects is "experience". However, rationalists claim that experience is "one" of the ways. By the linking of previous information, a series of new information can also be obtained. Relating information to each other for obtaining other information is interpreted as proof or argumentation (Al-Tusi, 1947).

Many Muslim scholars in their work have combined these two methods of argumentation and experience. For example, Ibn Sina has compiled the principles of medicine from the general ideas of cosmology that was derived from wisdom (philosophy in the general sense), using the method of observation and induction from empirical results and observations. Additionally, he has also done several empirical considerations in meteorology about the reflection of light in water particles to find out the nature of the rainbow by using the general ${ }^{2}$ It means preference of one thing over the other without a justified cause. 
principles or the philosophical fundamentals of natural sciences (Ibn Sina, 1983). Moreover, there is a purely argumentative deductive identification in every experimental characterization and it is the basis of empirical characterization. Therefore, intellect takes precedence over experience, that is, if there were no intellectual characterization of an argumentation based on the initial axioms, then the logic empirical characterization was impossible.

\section{Conclusion}

Contrary to analyses that the epistemic collection of pre-Renaissance sciences lacks any empirical content or scientific method in the new sense, or that these sciences are mysterious or a type of superstition, one can contend that part of these sciences that is dedicated to natural and technical research deeply possesses empirical contents and scientific method.

Although the natural sciences offered by Muslim scholars are in accordance with the experimental principles and satisfy all the characteristics of natural sciences, it is an oriented science with the divine characteristics. Indeed, Islamic natural sciences are based on the assumptions and fundamentals of religious anthropology and cosmology in the framework of Islamic philosophy and organized in accordance with religious goals and values.

In the view of Muslim scholars, the real knowing of any object is knowing of the essence of that object and of its relation to the Creator, who is the origin of all beings, and the essence of all objects comes from Him. What is obtained from observation, experience, and the following induction is the apparent aspects of the object. The real science must connect these appearances and phenomena to the interior of the objects, and acquire knowledge of the substance of the beings.

Investigating the nature of the universe is not just to studying the phenomena and finding a series of relationships between them, but it is the study of phenomena and appearance of objects in the light of their relationship with their inner nature, and it is a research about a part in the context of its relationship with the whole.

\section{Acknowledgements}

M. M. acknowledges financial support from the CAS-TWAS President's Fellowship Programme.

\section{Conflicts of Interest}

The author declares no conflicts of interest regarding the publication of this paper.

\section{References}

Abdullah, M., \& Nadvi, M. J. (2011). Understanding the Principles of Islamic World-View. The Dialogue, 6, 268-289.

Al-Farabi. (1996). kitāb ihsā' al-'ulūm (On the Introduction of Knowledge). Beirut: Dar al-Maktabah al-Halal. 
Al-Nafis. (1988). Kitab Sharh Tashreeh Al-Qanun (Commentary on the Anatomy of the Canon). Cairo: The Supreme Council for Culture and the Egyptian Book Burea.

Al-Tusi, K. N. (1947). Asas al-iqtibas (The Ground for the Acquisition of Knowledge). Tehran: Tehran University Press.

Azram, M. (2012). Epistemology: An Islamic Perspective. IIUM Engineering Journal Engineering Journal, 12. https://doi.org/10.31436/iiumej.v12i5.240

Barbour, I. G. (1968). Science and Religion Today. In I. G. Barbour, Ed., Science and Religion: New Perspectives on the Dialogue (pp. 3-29). New York: Evanston and London: Harper \& Row.

Dallal, A. (2002). Islamic Paradigms for the Relationship between Science and Religion. In T. Peters, M. Iqbal, \& S. Nomanul Haq, Eds., God, Life, and the Cosmos: Christian and Islamic Perspectives. London: Routledge.

Falagas, M. E., Zarkadoulia, E. A., \& Samonis, G. (2006). Arab Science in the Golden Age (750-1258 C.E.) and Today. The FASEB Journal, 20, 1581-1586. https://doi.org/10.1096/fj.06-0803ufm

Ferngren, G. B. (2002). Science and Religion: A Historical Introduction. Baltimore: JHU Press.

Golshani, M. (1998). Can Science Dispense with Religion?(3rd Edition). Tehran: Institute for Humanities and Cultural Studies.

Golshani, M. (2005). Sacred Science vs. Secular Science. In Z. A. Bagir, Ed., Science and Religion in a Post-Colonial World (pp. 77-102). Adelaide: AFT Press.

Hall, M. B. (1994). The Scientific Renaissance: 1450-1630. New York: Dover Publications.

Hoodbhoy, P. (1991). Islam and Science: Religious Orthodoxy and the Battle for Rationality. London: Zed Books Ltd.

Hunke, S. (1960). Allahs Sonne über dem Abendland (Allah's Sun over the Occident). Stuttgart: Unser arabisches Erbe.

Ibn Sina, A. (1983). al-Shifa: Al-Tabiaat. Qom: Marashi Najafi Library.

Iqbal, M. (2009). The Making of Islamic Science. Kuala Lumpur: Islamic Book Trust.

Kalin, I. (2002). Three Views of Science in the Islamic World. In T. Peters, M. Iqbal, \& S. Nomanul Haq (Eds.), God, Life, and the Cosmos: Christian and Islamic Perspectives (34 p.). London: Routledge. https://www.taylorfrancis.com/books/9781315253992

Nasr, S. H. (1981). Knowledge and the Sacred. New York: Crossroad Pub.

Nasr, S. H. (1993). The Need for a Sacred Science. Surrey: Curzon.

Nasr, S. H. (2005). Spirituality and Science-Convergence or Divergence? In H. Oldmeadow (Ed.), The Betrayal of Tradition: Essays on the Spiritual Crisis of Modernity (pp. 275-286). Bloomington, IN: World Wisdom.

Nasr, S. H. (2007). Islamic Science: An Illustrated Study. Chicago: Kazi Publications.

Nuseibeh, S. (1996). Epistemology. In S. Nasr, \& O. Leaman (Eds.), History of Islamic Philosophy (pp. 1451-1478). London: Routledge.

Qutb, S. (2006). Basic Principles of the Islamic Worldview (David, R., Trans.). North Haledon, NJ: Islamic Publications International.

Stenberg, L. (1996). Seyyed Hossein Nasr and Ziauddin Sardar on Islam and Science: Marginalization or Modernization of a Religious Tradition. Social Epistemology, 10, 273-287. https://doi.org/10.1080/02691729608578819

Turner, H. R. (1997). Science in Medieval Islam: An Illustrated Introduction. Autin, TX: University of Texas Press. 